\title{
PHANTOM VIBRATION SYNDROME SEBAGAI DAMPAK DARI PENGGUNAAN SMARTPHONE YANG BERLEBIHAN PADA REMAJA
}

\section{Baiq Annisa Mulya Kartini}

Fakultas Kedokteran, Universitas Mataram, Indonesia

Email: baiqannisamulya@gmail.com

\begin{abstract}
Abstrak
Smartphone menjadi perangkat yang tak terkalahkan dalam kehidupan masyarakat karena memberikan berbagai kemudahan untuk mencari informasi, berkomunikasi, sebagai media untuk belajar dan hiburan. Disamping segudang manfaat smartphone, penggunaan smartphone yang berlebihan memiliki beberapa dampak negatif salah satunya adalah phantom vibration syndrome. Phantom vibration syndrome merupakan jenis halusinasi umum yang dilaporkan pengguna smartphone di populasi umum. Sindrom ini disebabkan karena berlebihan dalam penggunaan smartphone, yang merasakan seolah-olah smartphone mereka bergetar tetapi nyatanya tidak. Populasi yang paling tinggi dalam menggunakan smartphone adalah kelompok usia 18 hingga 34 tahun. Adapun faktor-faktor yang menyebabkan terjadinya PVS adalah pekerjaan, tempat menaruh smartphone, usia, frekuensi penggunaan per hari dan frekuensi penggunaan dalam mode getar. Gejala yang dapat terjadi berupa kecemasan dan rasa takut. Phantom vibration syndrome memiliki prevalensi yang tinggi sehingga diperlukan tatalaksana awal untuk menjegah terjadinya komplikasi.
\end{abstract}

Kata kunci: Smartphone; Phantom Vibration Syndrome; Remaja

\section{Abstract}

Smartphone devices have become unbeatable in people's lives because they provide various facilities for finding information, communicating, as a media for learning and entertainment. Besides many benefits of smartphones, excessive use of smartphones has several negative impacts, one of them is phantom vibration syndrome. Phantom vibration syndrome is a common type of hallucination reported by smartphone users in the general population. This syndrome is caused by overuse of smartphones, which feel as if their smartphone is vibrating but is not. The highest population in smartphone use is the age group of 18 to 34 years old. The factors that cause PVS are work, place on the smartphone, age, frequency of using per day and frequency using in vibrate mode. Symptoms that can occur are anxiety and fear. Phantom vibration syndrome has a high prevalence, so early treatment is needed to prevent complications.

Keywords: Smartphone; Phantom Vibration Syndrome; Teenager 


\section{Pendahuluan}

Kemunculan smartphone merupakan hasil dari perkembangan teknologi komunikasi yang sudah sangat cepat merambah ke semua lapisan dan menyebabkan perubahan pola kehidupan masyarakat (Kohar, Riadi dan Lutfi, 2015). Smartphone menjadi perangkat yang tak terkalahkan dalam kehidupan masyarakat karena memberikan berbagai kemudahan untuk mencari informasi, berkomunikasi, sebagai media untuk belajar dan hiburan (Haug et al., 2015).

Tingginya tingkat penggunaan smartphone, cenderung terjadi pada negara-negara kaya dan masyarakat dengan pendidikan dan pendapatan yang lebih tinggi. Sejak tahun 2013 tingkat penggunaan smartphone telah menanjak di berbagai negara, lebih dari 25 poin persentase meningkat di antara total populasi dalam skala besar ekonomi seperti Turki (+42 poin), Malaysia (+34), Chili (+26), dan Brasil (+26). Berdasarkan penelitian yang dilakukan oleh National Information Society Agency pada tahun 2012, persentase penggunaan smartphone di Malaysia pada tahun 2013 sebanyak 94,2\% dan tahun 2015 sebanyak 97,5\% (Selvaganapathy, Rajappan dan Dee, 2017).

Hampir di setiap negara, penduduk yang mendominasi penggunaan smartphone adalah mereka yang berusia 18 hingga 34 tahun karena jauh lebih memungkinkan menjadi pengguna dibandingkan mereka yang berumur 35 tahun ke atas (Poushter, 2016). Penduduk dalam rentang usia 10-24 tahun disebut dengan remaja (Menteri Kesehatan Republik Indonesia, 2014). Puslitbang PPI kominfo menyatakan bahwa pengguna terbesar smartphone pada tahun 2014 adalah kelompok usia 16-25 tahun dengan persentase 84,82\% (Kemenkominfo RI, 2015) dan di Korea pada tahun 2013 pengguna smartphone tertinggi adalah mereka yang berusia dua puluhan tahun dengan persentase sebesar 97,4\% (Selvaganapathy, Rajappan and Dee, 2017).

Dapat dilihat bahwa remaja merupakan pengguna terbesar smartphone di berbagai negara. Disamping segudang manfaat smartphone, penggunaan smartphone yang berlebihan memiliki beberapa dampak negatif terhadap gaya hidup manusia, khususnya pada remaja sebagai pengguna smartphone tertinggi (Pareek, 2017). Salah satu dampak dari penggunaan smartphone yang berlebihan adalah terjadinya phantom vibration syndrome yaitu halusinasi umum yang disebabkan karena penggunaan smartphone yang berlebihan (Lin et al., 2013).

Phantom vibration syndrome memiliki prevalensi yang tinggi sehingga tatalaksana awal diperlukan untuk mencegah terjadinya komplikasi lebih lanjut. Dalam tinjauan pustaka ini, penulis menggunakan remaja sebagai batasan karena remaja merupakan populasi dengan pengguna smartphone terbesar di berbagai negara dan dalam tinjauan pustaka ini akan dijelaskan mengenai apa itu phantom vibration syndrome, epidemiologi phantom vibration syndrome, faktor- faktor yang bisa menyebabkan phantom vibration syndrome, manifestasi klinis phantom vibration syndrome dan tatalaksana phantom vibration syndrome. 


\section{Metode Penelitian}

Metode yang digunakan dalam penulisan tinjauan pustaka ini yaitu dengan literature review, menggunakan literature searching. Pencarian Pustaka menggunakan alat bantu cari berbasis website yaitu Google, Google Scholar dan PubMed menggunakan kata kunci Smartphone AND Phantom Vibration Syndrome AND Teenager. Artikel yang dipilih adalah artikel penelitian, meta analysis, systematic literature review, dan narrative review. Publikasi berbahasa Inggris maupun Indonesia free full text. Total jurnal yang dipilih dalam literature review ini yaitu sebanyak 19 jurnal.

\section{Hasil dan Pembahasan}

\section{A. Definisi}

Phantom vibration syndrome merupakan jenis halusinasi umum yang dilaporkan pengguna smartphone di populasi umum (Lin et al., 2013). Istilah lain mengenai phantom vibration syndrome menurut $\mathrm{Mr}$ robert $\mathrm{D}$. jones pada tahun 2013 adalah gangguan yang disebabkan karena berlebihan dalam penggunaan smartphone, yang merasakan seolaholah smartphone mereka bergetar tetapi nyatanya tidak (Pareek, 2017).

\section{B. Epidemiologi}

Prevalensi PVS akibat penggunaan smartphone pada mahasiswa kedokteran di Iran adalah 54,3\%. Angka kejadiannya lebih tinggi pada siswa perempuan dibandingkan dengan laki-laki (Mohammadbeigi et al., 2017). Sedangkan pada mahasiswa kedokteran peserta magang di Taiwan, angka kejadian PVS sebesar 78,1\% pada awal magang dan kejadiannya meningkat menjadi 95,9\% setelah 3 bulan (Lin et al., 2013). Pada penelian yang dilakukan Drouin Dkk (2012) terdapat 89\% responden yang mengalami phantom vibration syndrome. Penelitian yang dilakukan Goyal (2015) didapatkan dari 300 mahasiswa didapatkan $74 \%$ yang mengalami phantom vibration syndrome dan ringing syndrome (Setianingrum, 2017)(Goyal, 2015).

frekuensi gangguan phantom vibration syndrome dan phantom ringing syndrome

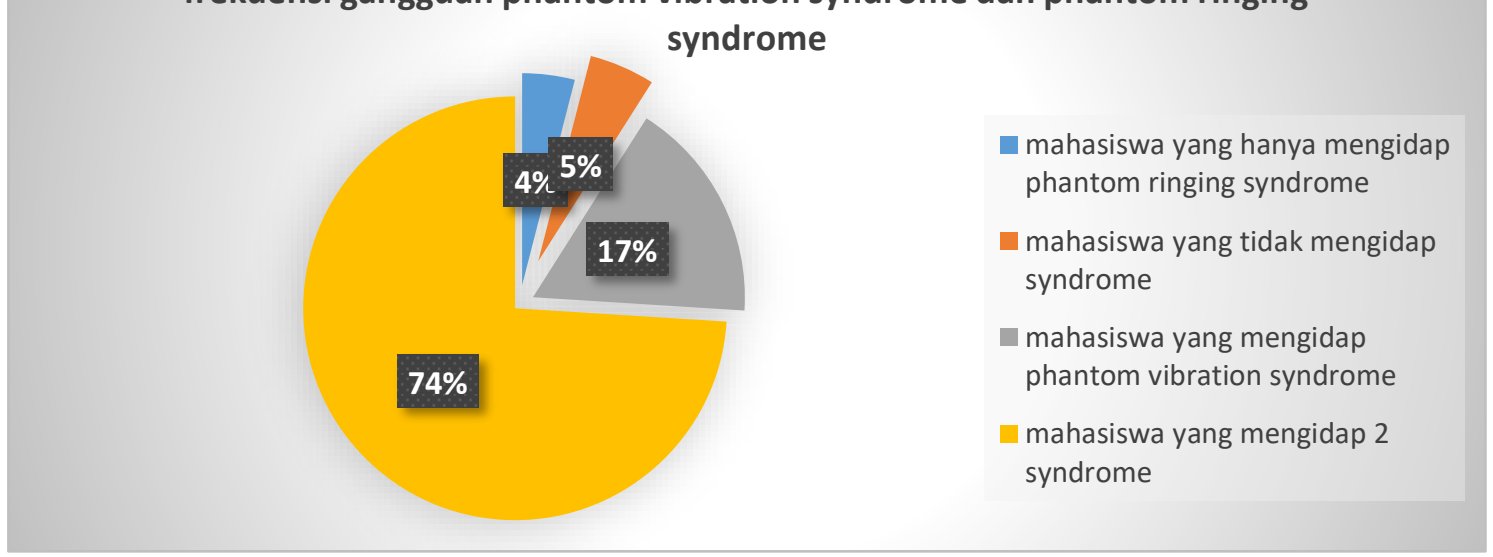

Grafik 2 Frekuensi Gangguan Phantom Vibration Syndrome dan Phantom Ringing Syndrome Sumber: (Goyal, 2015) 
Pada grafik diatas menunjukkan beberapa data mengenai persentase mahasiswa pascasarjana yang mengidap phantom vibration syndrome dalam penelitian Goyal tahun 2015.

\section{Faktor Risiko}

Adapun faktor-faktor yang menyebabkan terjadinya phantom vibration syndrome adalah pekerjaan, tempat menaruh smartphone yaitu menyimpan smartphone di saku yang sama untuk waktu yang lama, usia, frekuensi penggunaan smartphone, ketergantungan smartphone dan frekuensi penggunaan dalam mode getar (Rothberg et al., 2010).

Dalam penelitian Goyal pada tahun 2015 menyatakan bahwa faktor utama terkait PVS adalah tempat menaruh smartphone. Mahasiswa yang menaruh smartphone di saku baju dan saku depan jeans memiliki frekuensi PVS lebih tinggi dibandingkan dengan mahasiswa yang menaruh smartphone di saku belakang jeans dan frekuensi dari PVS paling rendah pada mahasiswa yang menaruh smartphone di tas tangan.

Berikut merupakan grafik yang menunjukan perbandingan jumlah mahasiswa yang menaruh smartphone mereka di saku baju, saku depan jeans, saku belakang jeans, dan tas tangan, dengan jumlah mahasiswa yang mengalami PVS.

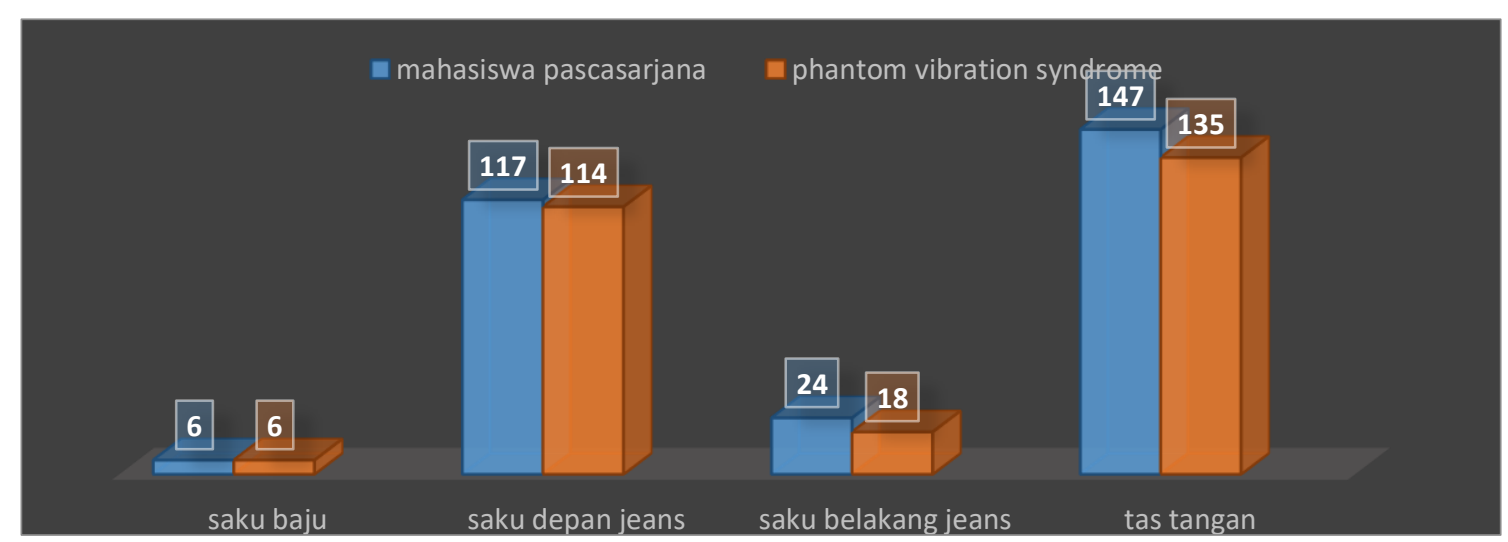

Grafik 1 Perbandingan Jumlah Mahasiswa dengan Pengidap Phantom Vibration Syndrome

Sumber: (Goyal, 2015)

Dilarangnya penggunaan mode dering dan getaran pada sebagian besar kantor, mengakibatkan pengguna beralih dengan menggunakan mode getar (Pareek, 2017). Berdasarkan penelitian yang dilakukan Mohammadbeigi Dkk (2017) terdapat hubungan yang signifikan antara phantom vibration syndrome dan penggunaan sosial media seperti Viber, WhatsApp, dan Line (Mohammadbeigi et al., 2017)

\section{Manifestasi Klinis}

Gejala-gejala yang dapat terjadi saat seseorang mengalami phantom vibration syndrome adalah stress psikologis, depresi, gangguan emosi, kecemasan dan halusinasi karena pengguna selalu berfikir bahwa ada seseorang yang menelpon, mengirim pesan, email, atau mengirim file kepadanya (Pareek, 2017). Kemudian rasa takut atau kewaspadaan berlebihan yang dialami pengguna karena merasa memiliki ancaman kehilangan file atau data penting yang berada di smartphone (Goyal, 2015). 
Dari penelitian yang dilakukan oleh Goyal (2015) mengenai gejala yang disebabkan oleh phantom vibration syndrome pada mahasiswa pascasarjana bahwa 53\% mahasiswa mengaku tidak merasakan kecemasan terkait gejala phantom vibration syndrome dan $42 \%$ mahasiswa mengalami kecemasan terkait gejala phantom vibration syndrome.

Pada penelitian yang dilakukan Setianingrum (2017) didapatkan bahwa seseorang yang memiliki gejala phantom vibration syndrome akan memiliki hubungan terhadap keadaan stress yang dirasakan seseorang. Phantom vibration syndrome memberikan pengaruh berupa sleep apnea yaitu seseorang akan mengalami gangguan pernapasan, rasa mengantuk, peningkatan tekanan darah, serangan jantung, stroke dan diabetes (Setianingrum, 2017). Apabila tidak ditangani dapat menimbulkan beberapa komplikasi seperti burnout syndrome, gangguan afektif psikologis, psikosis depresi dan stres patologis (Pareek, 2017).

\section{E. Tatalaksana}

Phantom vibration syndrome memiliki tingkat prevalensi yang tinggi dan itu muncul seiring waktu sehingga tatalaksana awal pada phantom vibration syndrome sangat penting. Untuk mengatasi phantom vibration syndrome dapat dilakukan dengan mengurangi penggunaan smartphone, modifikasi gaya hidup, meminimalisir penggunaan mode getar dengan tingkat keberhasilan $75 \%$, mengubah tempat menyimpan smartphone dengan tingkat keberhasilan $63 \%$ dan penggunaan jenis smartphone yang berbeda dengan tingkat keberhasilan 50\% (Pareek, 2017).

\section{Kesimpulan}

Secara garis besar, teknologi yang semakin berkembang secara pesat dan dapat merambah ke segala lempeng dunia, sehingga dapat dengan cepat merubah pola kehidupan masyarakat terutama remaja karena remaja merupakan pengguna tertinggi smartphone. Kemunculan smartphone merupakan salah satu dari hasil perkembangan teknologi. Namun dengan segudang manfaat smartphone, berbagai dampak negatif yang dapat mempengaruhi gaya hidup manusia contohnya phantom vibration syndrome yang merupakan gangguan karena berlebihan dalam penggunaan smartphone dan halusinasi seakan-akan mereka merasakan smartphone bergetar akan tetapi nyatanya tidak bergetar. Phantom vibration syndrome mempunyai faktor-faktor penyebab yang variatif dan gejala-gejala yang mudah dikenali. Cara mengatasi phantom vibration syndrome adalah dengan mengubah beberapa pola atau kebiasan yang sering dilakukan. Namun yang terpenting adalah bagaimana masyarakat atau remaja pada khususnya merubah sikap menjadi lebih dewasa dan bijak dalam melakukan aktivitas, termasuk dalam mengatur penggunaan smartphone dengan tepat. Masyarakat atau remaja pada khususnya akan terhindar dari berbagai penyakit akibat penggunaan smartphone termasuk phantom vibration syndrome. 


\section{BIBLIOGRAFI}

Goyal, A. K. (2015) 'Studies on phantom vibration and ringing syndrome among postgraduate students', Indian Journal of Community Health, 27(1), pp. 35-40. Google Scholar

Haug, S. et al. (2015) 'Smartphone use and smartphone addiction among young people in Switzerland', Journal of Behavioral Addictions, 4(4), pp. 299-307. doi: 10.1556/2006.4.2015.037. Google Scholar

Heo, J. et al. (2014) 'Addictive internet use among Korean adolescents: A national survey’, PLoS ONE, 9(2), pp. 1-8. doi: 10.1371/journal.pone.0087819. Google Scholar

Lin, Y. H. et al. (2013) 'Prevalent Hallucinations during Medical Internships: Phantom Vibration and Ringing Syndromes', PLOS ONE, 8(6), pp. 6-11. doi: 10.1371/journal.pone.0065152. Google Scholar

Kemenkominfo RI (2015) 'Buku Saku Data dan Tren TIK Indonesia 2015', p. 23. Available at: http://perpustakaan.bappenas.go.id/lontar/file?file=digital/163006[_Konten_]-Konten D1275.pdf. Google Scholar

Kementerian Kesehatan RI (2015) 'Infodatin Reproduksi Remaja-Ed.Pdf', pp. 1-8. doi: 24427659. Google Scholar

Menteri Kesehatan Republik Indonesia (2014) 'Peraturan Menteri Kesehatan Republik Indonesia Nomor 25 Tahun 2014 Tentang Upaya Kesehatan Anak', Menteri Kesehatan Republik Indonesia, p. 28. doi: 10.1017/CBO9781107415324.004. Google Scholar

Mohammadbeigi, A. et al. (2017) 'The prevalence of phantom vibration/ringing syndromes and their related factors in Iranian' students of medical sciences', Asian Journal of Psychiatry. Elsevier B.V., 27, pp. 76-80. doi: 10.1016/j.ajp.2017.02.012. Google Scholar

Pareek, S. (2017) 'Phantom Vibration Syndrome: An Emerging Phenomenon', Asian Journal of Nursing Education and Research, 7(4), p. 596. doi: 10.5958/23492996.2017.00116.1. Google Scholar

Rothberg, M. B. et al. (2010) 'Phantom vibration syndrome among medical staff: a cross sectional survey’, Bmj, 341(dec15 2), pp. c6914-c6914. doi: 10.1136/bmj.c6914. Google Scholar

Setianingrum, A. Y. (2017) 'Hubungan Phantom Vibration Syndrome Terhadap Sleep Disorder dan Kondisi Stress', Jurnal Optimasi Sistem Industri, 16(2), p. 158. doi: 10.25077/josi.v16.n2.p158-166.2017. Google Scholar

Poushter, J. (2016) 'Smartphone Ownership and Internet Usage Continues to Climb in Emerging Economies', Pew Research Center, pp. 1-45. doi: 10.1017/CBO9781107415324.004. Google Scholar

Selvaganapathy, K., Rajappan, R. and Dee, T. H. (2017) 'the Effect of Smartphone Addiction on Craniovertebral Angle and Depression Status Among University 
Students', International Journal of Integrative Medical Sciences, 4(7), pp. 537542. doi: 10.16965/ijims.2017.118. Google Scholar

Thomée, S., Härenstam, A. and Hagberg, M. (2011) 'Mobile phone use and stress, sleep disturbances, and symptoms of depression among young adults - A prospective cohort study', BMC Public Health, 11. Google Scholar

First publication right:

Jurnal Syntax Fusion: Jurnal Nasional Indonesia

This article is licensed under:

(c) (7) (2) 